\title{
Estimation of wheat crop evapotranspiration using NDVI vegetation index
}

\author{
Sirisha Adamala ${ }^{1 *}$, Yogesh Anand Rajwade ${ }^{1}$, and Y.V. Krishna Reddy ${ }^{2}$ \\ ${ }^{1}$ Agricultural and Food Engineering Department, Indian Institute of Technology, Kharagpur-721302, (West Bengal), \\ INDIA \\ ${ }^{2}$ Central Research Institute for Dryland Agriculture (CRIDA), Hyderabad-500059, (Telangana), INDIA \\ *Corresponding author. E-mail: sirisha@agfe.iitkgp.ernet.in
}

Received: April 26, 2015; Revised received: November 6, 2015; Accepted: February 6, 2016

\begin{abstract}
The evapotranspiration of the wheat crop grown in Tarafeni South Main Canal (TSMC) irrigation command area of West Bengal, India was estimated based on Normalized Difference Vegetation Index (NDVI) from LANDSAT images. The crop evapotranspiration $\left(\mathrm{ET}_{\mathrm{c}}\right)$ of wheat crop was estimated using the crop coefficient $\left(\mathrm{K}_{\mathrm{c}}\right)$ maps and the reference evapotranspiration $\left(E T_{0}\right)$ in the TSMC irrigation command area. The $E T_{0}$ was estimated from the well known temperature based $\mathrm{ET}_{0}$ estimation method, i.e. FAO-24 modified Blaney-Criddle method using measured maximum and minimum air temperatures data during January 2011 in the command area. The $\mathrm{K}_{\mathrm{c}}$ maps were mapped in ARC GIS software using procured LANDSAT images for the study period. The area under wheat crop was clipped from land use/land cover map generated from LANDSAT image of January, 2011 for winter season. Further, the crop evapotranspiration map was obtained by multiplying $\mathrm{K}_{\mathrm{c}}$ map with the estimated $\mathrm{ET}_{\mathrm{o}}$ value i.e., $5.76 \mathrm{~mm} /$ day for a particular day. The maximum crop evapotranspiration computed for Rabi crop was $5.57 \mathrm{~mm} /$ day, whereas minimum was $1.59 \mathrm{~mm} /$ day for the TSMC command area.
\end{abstract}

Keywords: Crop coefficient, Irrigation, Reference evapotranspiration, Remote sensing, Vegetation index.

\section{INTRODUCTION}

Increasing water scarcity has lead to increased pressure on irrigation engineers to utilize water resources more efficiently for irrigation (Adamala et al., 2014). For effective water management, the estimation of evapotranspiration is vital. Unfortunately, for effective water management, large irrigation schemes need up-to-date real time information on the irrigated area, the crops being grown within the command area of each canal, and also the data on the amount of water being used by each crop. This information is not easy to obtain as many irrigation schemes are vast, cover hundreds, and sometimes thousands of square miles and have vast numbers of farms; their scale severely limiting the effectiveness of data collection. Satellite images provide a powerful tool for the identification of crops and when used in conjunction with geographical information systems (GIS) have proved to be effective for land use and crop identification (Gontia and Tiwari, 2010).

Crop evapotranspiration $\left(\mathrm{ET}_{\mathrm{c}}\right)$ represents crop water demand and governed by weather and crop conditions and most of the current water demand models are non-spatial models, they use point data of reference evapotranspiration $\left(\mathrm{ET}_{\mathrm{o}}\right)$ and crop coefficient values from available literature (Doorenbos and Pruitt, 1977). Crop coefficient $\left(\mathrm{K}_{\mathrm{c}}\right)$ is an important parameter for irrigation scheduling and water allocation. Crop coefficient values taken from literature may provide a practical guideline for scheduling irrigation, but considerable error in estimating crop water requirement can occur due to their empirical nature (Jagtap and Jones, 1989). Therefore, it becomes necessary to make corrections in crop coefficient values as per local conditions. Wheat (Triticum aestivum L.) is the most important cereal crop after rice in West Bengal, India. Bandyopadhyay and Mallick (2003) estimated $\mathrm{K}_{\mathrm{c}}$ values for wheat crop at four crop growth stages namely initial, crop development, mid season, and maturity for local conditions of West Bengal, India. Satellite remote sensing gives opportunities to monitor land surface conditions and status of water resources on different spatial and temporal resolutions. The need arises to utilize remote sensing for estimating crop water requirement in irrigation commands. The crop coefficient generated from remote sensing responds to actual crop condition in a field and captures the variability among different fields, which occurs due to different dates of sowing of wheat crop, soil and field conditions.

Mishra et al. (2005) estimated crop coefficients of paddy crop grown in irrigation command using remote sensing data; however, the impounded water background in paddy fields might have influenced the crop reflectance and affected the results to a great extent. Scientists used remote sensing based vegetation indices for predicting crop water requirement on large scale (Ray and Dadhwal 2000; Gontia and Tiwari 2004 etc.). Allen et al. (2005) described the development ISSN : 0974-9411 (Print), 2231-5209 (Online) All Rights Reserved @ Applied and Natural Science Foundation www.ansfoundation.org 
procedure and figures for estimating $\mathrm{K}_{\mathrm{c}} . \mathrm{K}_{\mathrm{c}}$ varies with wetting frequency, evaporative demand, and waterholding capacity of the upper soil layer. Jayanthi et al. (2007) estimated daily $\mathrm{ET}_{\mathrm{c}}$ for potato using basal and canopy reflectance based crop coefficients. They used hand-held radiometers and high resolution multispectral digital imagery and studied hydrologic water balance in the plant root zone. High resolution multispectral aerial imagery was used to highlight the spatial variability of actual crop water demand in the study fields. Thus both the crop coefficients and vegetation indices (derived from reflectance) are affected by leaf area index and fractional ground cover. These can be correlated and crop coefficients can be generated using remote sensing derived spatially and temporally distributed vegetation indices. Remote sensing assists in estimation of crop evapotranspiration on large aerial extent in irrigation commands in short period of time, economically and with reliability. In some of the cases actual $\mathrm{K}_{\mathrm{c}}$ values are significantly different from those suggested by the Food and Agricultural Organization of the United Nations indicating the need for generating these values at the local/regional level (Bandyopadhyay and Mallick, 2003). The present study has been undertaken to estimate evapotranspiration demand of wheat crop for irrigation scheduling in Tarafeni South Main Canal (TSMC) irrigation command using Normalized Difference Vegetation Index (NDVI) vegetation index.

\section{MATERIALS AND METHODS}

Study area: The study was conducted to estimate the crop evapotranspiration through remote sensing and GIS techniques for Tarafeni South Main Canal (TSMC) Command area. The study area is located between $86^{\circ} 45^{\prime} \mathrm{E}$ to $87^{\circ} 15^{\prime} \mathrm{E}$ longitude and $22^{\circ} 15^{\prime} \mathrm{N}$ to $22^{\circ} 45^{\prime} \mathrm{N}$ latitude is a part of right bank main canal of Kangsabati project and supplemented with a barrage on Tarafeni river in the Pashchim Midnapur districts of West Bengal state of India. The gross irrigation command area of TSMC is about 70,450 ha and major crops grown are paddy in monsoon season, wheat, potato, mustard and vegetables in winter season (Gontia and Tiwari, 2004). At present overall irrigation efficiency (the ratio of water available for crop to the water supplied from reservoir) for paddy crop is $37 \%$ and about $45 \%$ for other crops as per the annual report2001 of Kangsabati Command Area Development Authority (Gontia and Tiwari, 2010). Low irrigation efficiency can be improved by proper irrigation scheduling as per crop water demand. About $50 \%$ of irrigation command area is under cultivation, more than $40 \%$ area is covered by forest, and remaining area is orchards, fallow land, wasteland and establishments. Soil of the location is acid lateritic with sandy loam in texture. The climate of TSMC Command area is classified as humid and subtropical. It is characterized as hot and humid in the summer (April and May), rainy during June to September, moderately hot and dry in autumn (October and November), cool and dry in winter (December and January), and moderate in spring (February and March). The site receives an average annual rainfall of $1400 \mathrm{~mm}$ with an occurrence of $70-75 \%$ of the total rainfall in the monsoon months (June to October). The average daily temperature varies between $21{ }^{\circ} \mathrm{C}$ in December/January and $32{ }^{\circ} \mathrm{C}$ in May/June.

Data used: To conduct this study, various satellites based and climatic data was used which is mentioned in Table 1. The LANDSAT satellite image (Fig. 2) with 10-01-2011 date of passing was downloaded from United States Geological Survey (USGS) website (http://www.usgs.gov/pubprod/aerial.html\#satellite). The topographic sheets of Kolkata and Jamshedpur required for this study were obtained from University of Texas Libraries (http://www.lib.utexas.edu/maps/ ams/india/). As the TSMC command area falls in the states of Kolkata and Jamshedpur, both of their topographic sheets was merged to obtain the study map of TSMC command area (Fig. 3). Landsat 5 Thematic Mapper (TM) has 7 different bands with different characteristics which are shown in Table 2. The data acquired by this satellite is for every 16 days. These bands are useful for extracting various information related to vegetation, temperature, clouds, soil moisture, biomass, rocks, minerals, etc. The software used for processing various satellite images and conducting this study were include: Erdas Imagine 9.1, Arc GIS 9.3, and Google Earth Pro.

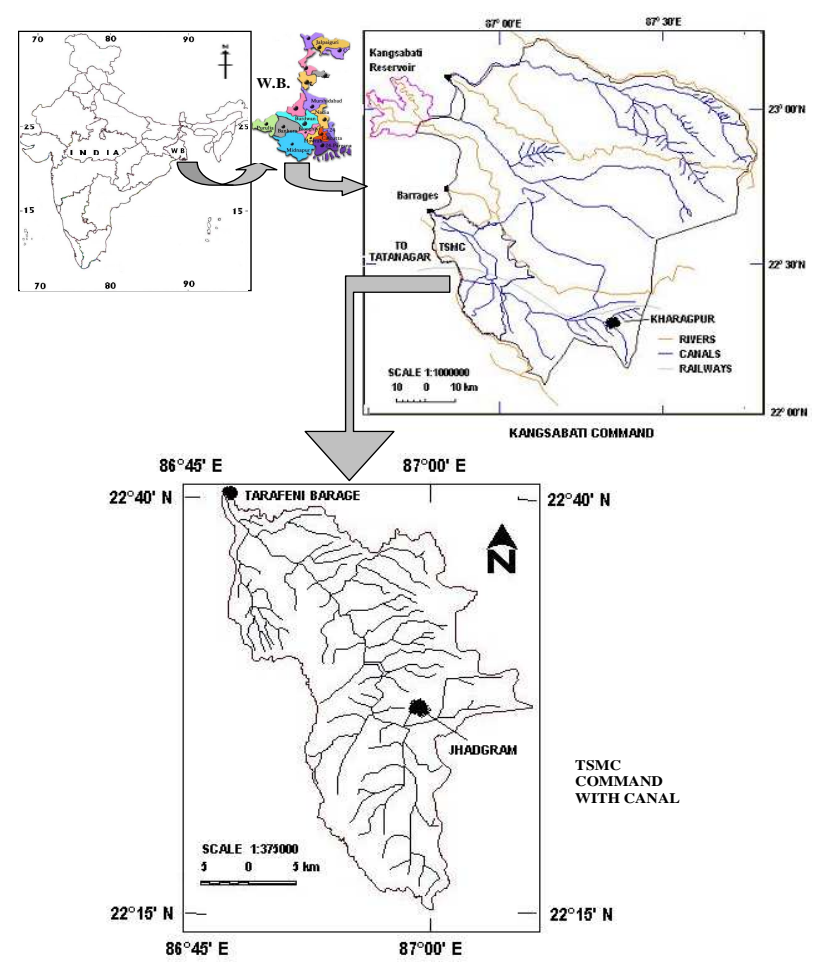

Fig. 1. Location map of the Tarafeni south main canal (TSMC) command area . 
Calculation of reference evapotranspiration $\left(\mathbf{E T}_{\mathbf{0}}\right)$ : The collected meteorological data was used to compute $\mathrm{ET}_{\mathrm{o}}$ using FAO-24 modified Blaney-Criddle method (Eq. 1). The reason for selecting this method for computation of $\mathrm{ET}_{\mathrm{o}}$ because of its simplicity and easy availability of data.

$$
\mathrm{ET}_{o}=\mathrm{p}\left(0.46 * \mathrm{~T}_{\text {mean }}+8\right)
$$

Where, $\mathrm{ET}_{\mathrm{o}}=$ Reference crop evapotranspiration $(\mathrm{mm}$ day $^{-1}$ ) as an average for a period of one month, $\mathrm{T}_{\text {mean }}=$ Mean daily air temperature $\left({ }^{\circ} \mathrm{C}\right), \mathrm{p}=$ Mean daily percentage of annual daytime hours.

Calculation of crop coefficients $\left(\mathbf{K}_{\mathbf{c}}\right)$ : The crop coefficients for various major crops grown in TSMC command area can be estimated empirically from the remote sensing derived vegetation index i.e. normalized difference vegetation index (NDVI) values. In order to calculate NDVI, we first need to calculate the spectral radiance and then reflectance for Band 3 (Red) and Band 4 (Near Infrared). Spectral radiance is the outgoing radiation energy of the band as observed at the top of the atmosphere by the satellite. The four steps in order to calculate $\mathrm{K}_{\mathrm{c}}$ is provided in detail below:

Step 1: Conversion from digital number to spectral radiance as:

$$
\mathrm{L}=\frac{\left(\mathrm{L}_{\max }-\mathrm{L}_{\text {min }}\right) *\left(\mathrm{Q}_{\text {cal }}-\mathrm{Q}_{\text {calmin }}\right)}{\left(\mathrm{Q}_{\text {calmax }}-\mathrm{Q}_{\text {calmin }}\right)}+\mathrm{L}_{\text {min }}
$$

Where, $\mathrm{L}=$ Spectral radiance at the sensor aperture (watt $\mathrm{m}^{-2}$ ster $^{-1} \mu \mathrm{m}^{-1}$ ), $\mathrm{L}_{\max }=$ Spectral radiance scaled to $\mathrm{Q}_{\text {calmax }}\left(\right.$ watt $\mathrm{m}^{-2} \operatorname{ster}^{-1} \mu \mathrm{m}^{-1}$ ), $\mathrm{L}_{\text {min }}=$ Spectral radiance scaled to $\mathrm{Q}_{\text {calmin }}$ (watt $\mathrm{m}^{-2} \mathrm{ster}^{-1} \mu \mathrm{m}^{-1}$ ), $\mathrm{Q}_{\text {cal }}=$ Quantized calibrated pixel value $(\mathrm{DN}), \mathrm{Q}_{\text {calmin }}=$ Minimum quantized calibrated pixel value corresponding to $\mathrm{L}_{\min }, \mathrm{Q}_{\text {calmax }}=$ Maximum quantized calibrated pixel value corresponding to $\mathrm{L}_{\max }$.

From meta data header file, information which is obtained with the image from Global Land Cover Facility (GLCF) site (http://glcf.umd.edu/),

$\mathrm{Q}_{\text {calmax }}=255$, and $\mathrm{Q}_{\text {calmin }}=0$

For band 4: $\mathrm{L}_{\max }=221$ and $\mathrm{L}_{\min }=-1.51$

For band 3: $\mathrm{L}_{\max }=264$ and $\mathrm{L}_{\min }=-1.17$

Step 2: Conversion from radiance to reflectance as:

$$
\mathrm{r}=\frac{\pi * \mathrm{~L}^{*} \mathrm{~d}^{2}}{\mathrm{E}_{\mathrm{sun}} * \operatorname{Cos} \theta * \mathrm{dr}}
$$

Where, $r=$ Planetary reflectance (dimensionless), $\mathrm{L}=$ Spectral radiance at the sensor aperture (watt $\mathrm{m}^{-2}$ ster $^{-1}$ $\left.\mu \mathrm{m}^{-1}\right), \mathrm{d}_{\mathrm{r}}=$ Inverse square of earth-sun distance (astronomical unit).

$\left.\mathrm{d}_{\mathrm{r}}=1+0.033 \operatorname{Cos}(\mathrm{D} * 2 * 3.14) / 365\right)$

Where, $\mathrm{D}=$ Day of the year (352), $\mathrm{E}_{\text {sun }}=$ Mean solar atmospheric irradiances (watt $\mathrm{m}^{-2} \mu \mathrm{m}^{-1}$ ), $\quad \theta=$ Solar zenith angle (degree), $\theta=(90-\beta$ ), and $\beta=$ Sun elevation angle provided in LANDSAT header file i.e., 43.173 .

For band 4: $\mathrm{E}_{\mathrm{sun}}=1036$ watt $\mathrm{m}^{-2} \mu \mathrm{m}^{-1}$

For band 3: $\mathrm{E}_{\text {sun }}=1554$ watt $\mathrm{m}^{-2} \mu \mathrm{m}^{-1}$, and

\begin{tabular}{|c|c|c|c|}
\hline \multicolumn{4}{|l|}{ Satellite data } \\
\hline Satellite & Sensor & Row/Path & Date of passing \\
\hline Landsat 5 & $\mathrm{TM}$ & $139 / 44$ & 2011-01-10 \\
\hline \multicolumn{4}{|c|}{ Survey of India (SOI) topographic sheet } \\
\hline \multicolumn{4}{|c|}{ - Kolkata: Scale: 1:250,000 (NF 45-7) } \\
\hline \multicolumn{4}{|c|}{ - Jamshedpur: Scale: 1:250,000 (NF 45-6) } \\
\hline \multicolumn{4}{|c|}{ Meteorological data } \\
\hline \multicolumn{4}{|c|}{ - Latitude of TSMC command area } \\
\hline \multicolumn{4}{|c|}{ - Daily minimum and maximum temperatures for January, 2011} \\
\hline
\end{tabular}

Step 3: Computing NDVI from reflectance as:

Table 1. Data used for this study

\begin{tabular}{|c|c|c|c|c|}
\hline \multicolumn{2}{|c|}{ Spectral Bands } & \multirow{2}{*}{$\begin{array}{c}\begin{array}{c}\text { Wave- } \\
\text { length }(\boldsymbol{\mu m})\end{array} \\
0.45-0.52\end{array}$} & \multirow{2}{*}{$\begin{array}{l}\text { Potential Information Content } \\
\text { Discriminates soil and rock surfaces from vegetation. } \\
\text { Provides increased penetration of water bodies }\end{array}$} & \multirow{2}{*}{$\begin{array}{c}\begin{array}{c}\text { Resolution } \\
(\mathbf{m})\end{array} \\
30\end{array}$} \\
\hline Band 1 & Blue & & & \\
\hline Band 2 & Green & $0.52-0.60$ & Useful for assessing plant vigor & 30 \\
\hline Band 3 & Red & $0.63-0.69$ & Discriminates vegetation slopes & 30 \\
\hline Band 4 & Near IR & $0.76-0.90$ & Biomass content and shorelines & 30 \\
\hline Band 5 & Mid IR & $1.55-1.75$ & $\begin{array}{l}\text { Discriminates moisture content of soil and vegetation; } \\
\text { penetrates thin clouds }\end{array}$ & 30 \\
\hline Band 6 & Thermal IR & $10.4-12.5$ & Thermal mapping and estimated soil moisture & 120 \\
\hline Band 7 & Mid IR & $2.08-2.35$ & $\begin{array}{l}\text { Mapping hydrothermally altered rocks associated with } \\
\text { mineral deposits }\end{array}$ & 30 \\
\hline
\end{tabular}

Table 2. Various characteristics of Landsat5 TM. 


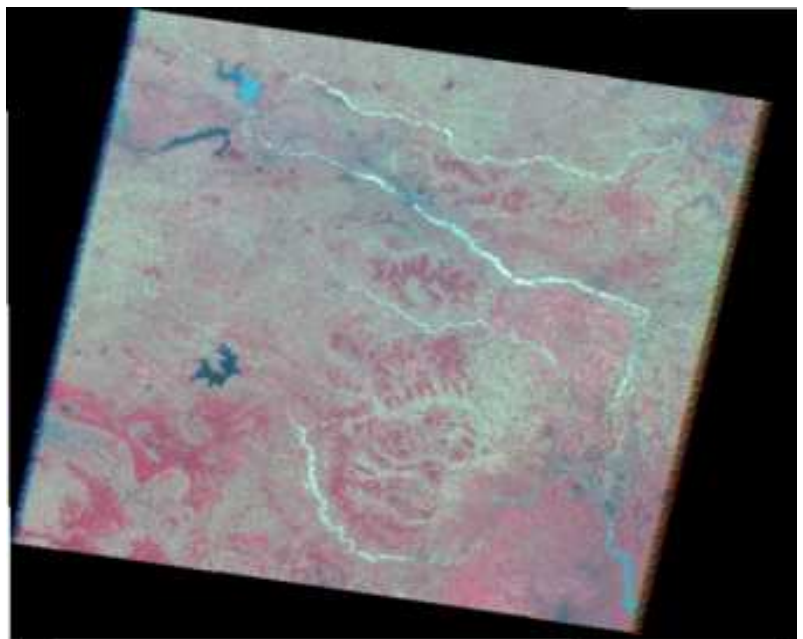

Fig. 2. Layer stacked image for the study area (Source: http://www.usgs.gov/pubprod/aerial.html\#satellite)

NDVI is a simple numerical index to assess the presence of live green vegetation. NDVI takes the value from -1 to 1 . The higher the NDVI, higher the fraction of live green vegetation present in the scene. Landsat band $4(0.77-0.90 \mu \mathrm{m})$ measures the reflectance in NIR region and Band $3(0.63-0.69 \mu \mathrm{m})$ measures the reflectance in Red region. The model for calculating NDVI for each pixel from classified map is given below:

$$
\mathrm{NDV} I=\frac{\mathrm{N} I R-\mathrm{R}}{\mathrm{NIR}+\mathrm{R}}
$$

Where, NIR = Reflectance in near infrared wavelength and $\mathrm{R}=$ Reflectance in red wavelength.

Step 4: Computing crop coefficients $\left(\mathrm{K}_{\mathrm{c}}\right)$ as:

The method proposed by Brunsell and Gillies (2002) to obtain the $\mathrm{K}_{\mathrm{c}}$ values for Rabi crop was used here. The method computes the $K_{c}$ based on fraction of vegetation cover and fraction between the emissivity of bare soil and a full canopy.

$$
\mathrm{N}=\frac{\left(\mathrm{NDVI}_{-}-\mathrm{NDVI}_{0}\right)}{\left(\mathrm{NDVI}_{\max }-\mathrm{NDVI}_{0}\right)}
$$

Where, $\mathrm{NDVI}_{0}=$ Bare soil NDVI value of the Landsat scene and $\mathrm{NDVI}_{\max }=$ Maximum NDVI of the scene corresponding to full cover dense vegetation.

Then crop coefficient becomes, $\mathrm{K}_{\mathrm{c}}=\mathrm{N}^{2}$

Calculation of crop evapotranspiration $\left(\mathbf{E T}_{\mathbf{c}}\right)$ : The calculated $\mathrm{ET}_{\mathrm{o}}$ from FAO-24 modified Blaney-Criddle method is combined with developed $\mathrm{K}_{\mathrm{c}}$ maps to compute crop evapotranspiration for TSMC command area.

$$
\mathrm{ET}_{\mathrm{c}}=\mathrm{K}_{\mathrm{c}} * \mathrm{ET}_{\mathrm{o}}
$$

Fig. 4 showing the procedure adopted for computing crop evapotranspiration $\left(\mathrm{ET}_{\mathrm{c}}\right)$ for this study.

\section{RESULTS AND DISCUSSION}

Generation of false colour composite (FCC) map: For getting required study area i.e. Tarafeni South Main Canal (TSMC), it is necessary to digitize boundary

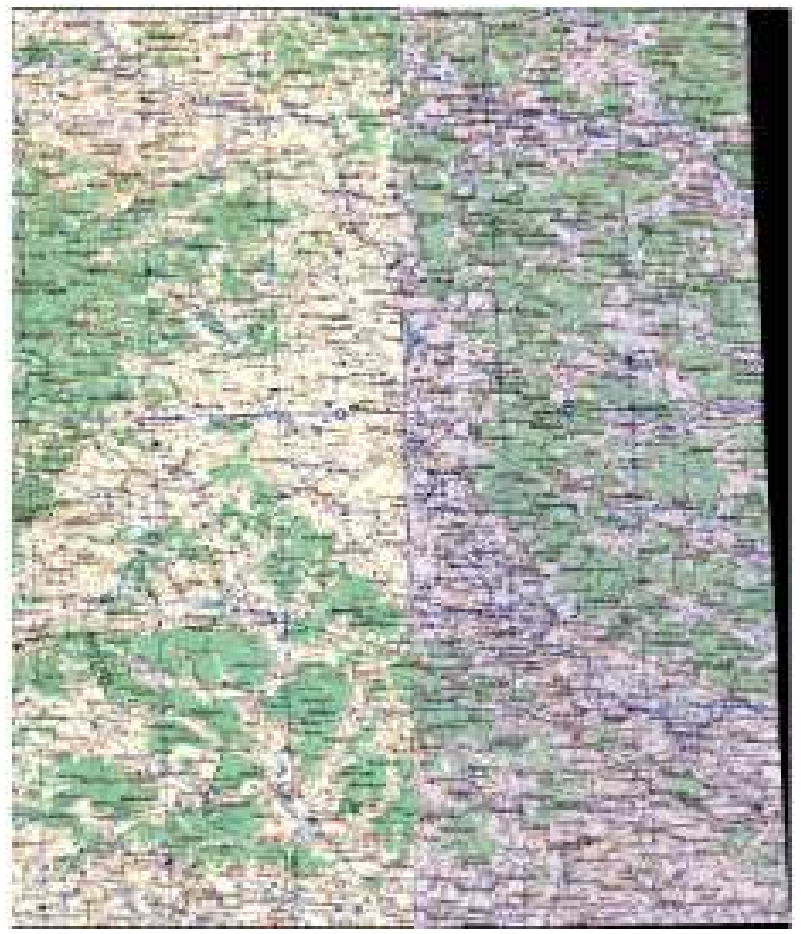

Fig. 3. Mosaic of two topographic maps (Kolkata and Jamshedpur) for getting required the study area (Source: http://www.lib.utexas.edu/maps/ams/india/)

of an irrigation command area. But because of presence of the study area in both the topographic maps i.e. Kolkata and Jamshedpur, it is required to perform 'mosiacking'. Mosaicking is the process of combining multiple images into a single composite image. It can be used to combine pixel-based images, to lay out images for publication or map composition, or as a means for combining georeferenced images into an image covering a larger geographic area. The False Colour Composite (FCC) of image with bands 1, 2, and 3 (Green, Red, and NIR bands, respectively) is shown in Fig. 5. Since, it is false color composite, vegetation is represented red color due to its high reflectance in the near infrared spectral band, which was used as the red component in the color composite. The sample profile of selected bands of FCC shows that the band 1 (Green band) has higher gray values followed by band 2 and band 3 (Red and NIR band), respectively. A false color composite of near infrared is useful for observing spatial distribution of the vegetation in the Landsat scene.

Generation of Land Use Land Cover (LULC) Map: The Land use land cover (LULC) map of winter season of TSMC irrigation command was prepared for the study area occupied by different classes. The LULC classes of TSMC irrigation command in winter season include water bodies, desert forest, orchards, fallow lands, Rabi crop, vegetation, and establishments/sandy lands as shown in Fig. 6. The unsupervised classification was performed on the FCC image and the final output map of the land use land cover of TSMC command is 
shown in Fig. 6. In the unsupervised classification the pixels in an image are examined and aggregated into a number of spectral classes based on the natural grouping or clusters present in the image value. Because the spectral classes are based on the natural groupings in the image values, their identity is not known initially. Therefore, the classified data was compared with the reference data or ground truths to determine the identity and informational value of the spectral classes. For statistical analysis of land use land cover classification the error (confusion) matrix of land use land cover classification of winter season was developed. It was found that for LULC classification of winter season the overall accuracy and overall Kappa statistics (k) were $78.00 \%$ and 0.712 , respectively. According to Manserud and Leemans (1992) these statistics revealed that the LULC classification is good and can be accepted for analysis.

Generation of radiance and reflectance maps: The radiance and reflectance maps of band 3 and band 4 required for NDVI calculation are shown in Figs. 7 and 8 . The results obtained by FAO-24 modified BlaneyCriddle method are shown as:

Mean air temperature $\left(\mathrm{T}_{\text {mean }}\right)$ for January, $2011=25.18{ }^{\circ} \mathrm{C}$ Latitude of the study area $=22{ }^{\circ} \mathrm{N}$

Therefore, for this latitude the value of $\mathrm{p}=0.294$

The calculated $\mathrm{ET}_{\mathrm{o}}=5.76 \mathrm{~mm} / \mathrm{day}$

Generation of normalized difference vegetation index (NDVI) maps: Fig. 9 shows the NDVI values for all land use land classes. Here, maximum NDVI value computed was 0.649 , whereas minimum is 0.219. Generally, NDVI values for vegetation, water, and bare soil are $>0.1,<0$ and 0 to 0.1 , respectively. Therefore, most of this study area falls under vegetation condition, as the NDVI value is $>0.1$. From ground truth analysis also it is conformed that this study area consists of most of the wheat crop cultivation. These results were also strengthening by the findings of Bhadra et al. (2009) and Bhadra et al. (2015).

Figs. 10 and 11 show that different NDVI values generated for only one land class i.e. Rabi (wheat) crop which can be obtained by clipping Rabi crop areas from base map (Google Earth Pro). This range of different NDVI values for Rabi crop can be obtained by classifying Fig. 11 by knowledge engineer classification. The results obtained are supporting the similar study conducted by Mishra et al. (2005) for paddy crop in TSMC irrigation command (West Bengal, India) and Ray and Dadhwal (2000) in Mahi river irrigation command (Gujarat, India). Therefore, the information generated can be used to supply appropriate amount of irrigation water at different locations of irrigation command as per the actual crop water demand.

Generation of crop coefficient $\left(\mathbf{K}_{\mathbf{c}}\right)$ maps: The NDVI maps were generated for wheat cropped area of TSMC irrigation command, which have monitored for ground truths data also. For each site, the average values of NDVI were recorded. Crop coefficients of wheat crop were generated through satellite images of different dates. The vegetation index (NDVI) generated for wheat cropped area were correlated with the crop coefficients $\left(\mathrm{K}_{\mathrm{c}}\right)$ of Food and Agricultural Organization (FAO) to develop regression equations (Gontia and Tiwari, 2010). The $\mathrm{K}_{\mathrm{c}}$ values of wheat crop grown in local conditions of the study area (West Bengal, India) were developed by Bandyopadhyay and Mallick (2003) were also used in this study. Fig. 12 shows that the range of crop coefficient values for Rabi crops. The maximum $\mathrm{K}_{\mathrm{c}}$ computed is 0.56-0.97, whereas minimum is $0.0009-0.29$. From FAO 24 bulletin the range of 0.56-0.97 (Allen et al., 2005) is assigned to wheat crop for crop development stage where as 0.0009-0.29 assigned to crop initial stage. The reason for getting this variation in $K_{c}$ value is may be due to variation of different sowing rates. Similar type of crop coefficient values for this region was recommended by Bhadra et al. (2009).

Generation of crop evapotranspiration $\left(\mathrm{ET}_{\mathrm{c}}\right)$ maps: $\mathrm{ET}_{\mathrm{o}}$ values for January month of wheat crop were computed using FAO-24 modified Blaney-Criddle method (Eq. 1). The output of pixel-wise $\mathrm{K}_{\mathrm{c}}$ map was multiplied with computed reference evapotranspiration $\left(\mathrm{ET}_{\mathrm{o}}\right)$ in software ARC GIS to generate the $\mathrm{ET}_{\mathrm{c}}$ maps. Fig. 13 shows the crop evapotranspiration map generated from clipped Rabi crop area. The crop evapotranspiration map was obtained by multiplying $\mathrm{K}_{\mathrm{c}}$ map with the reference evapotranspiration i.e. 5.76 $\mathrm{mm} /$ day. The maximum crop evapotranspiration computed for Rabi crop is $5.57 \mathrm{~mm} /$ day, whereas minimum is $1.59 \mathrm{~mm} /$ day. Similar results of estimated average value of crop evapotranspiration were found by Gontia and Tiwari (2010) in this particular study area. Further, some of results were reported in the study conducted by Mishra et al. (2005) for paddy crop in TSMC irrigation command in West Bengal, India and Ray and Dadhwal (2000) in Mahi river irrigation command in Gujarat, India. Therefore, it can be concluded that this remote sensing based procedure is capable of estimating crop water requirement of the command satisfactorily for the wheat crop.

\section{Conclusion}

The crop evapotranspiration of the wheat crop grown in TSMC irrigation command area of West Bengal, India was estimated based on NDVI vegetation index of LANDSAT images $\left(\mathrm{K}_{\mathrm{c}}\right.$ maps) and the reference evapotranspiration $\left(\mathrm{ET}_{\mathrm{o}}\right.$ ) for irrigation command area. Based on these regression equations the $\mathrm{K}_{\mathrm{c}}$ maps were generated from NDVI values for January 2011 of the wheat crop season. The class accuracy statistics and overall Kappa statistics of the land classification was about $78.00 \%$ and 0.712 respectively. These values are satisfying the classification criteria of Manserud and Leemans (1992). The maximum NDVI computed was 0.649 , whereas minimum was -0.219 . The range of maximum $\mathrm{K}_{\mathrm{c}}$ computed was 0.56-0.97, whereas 


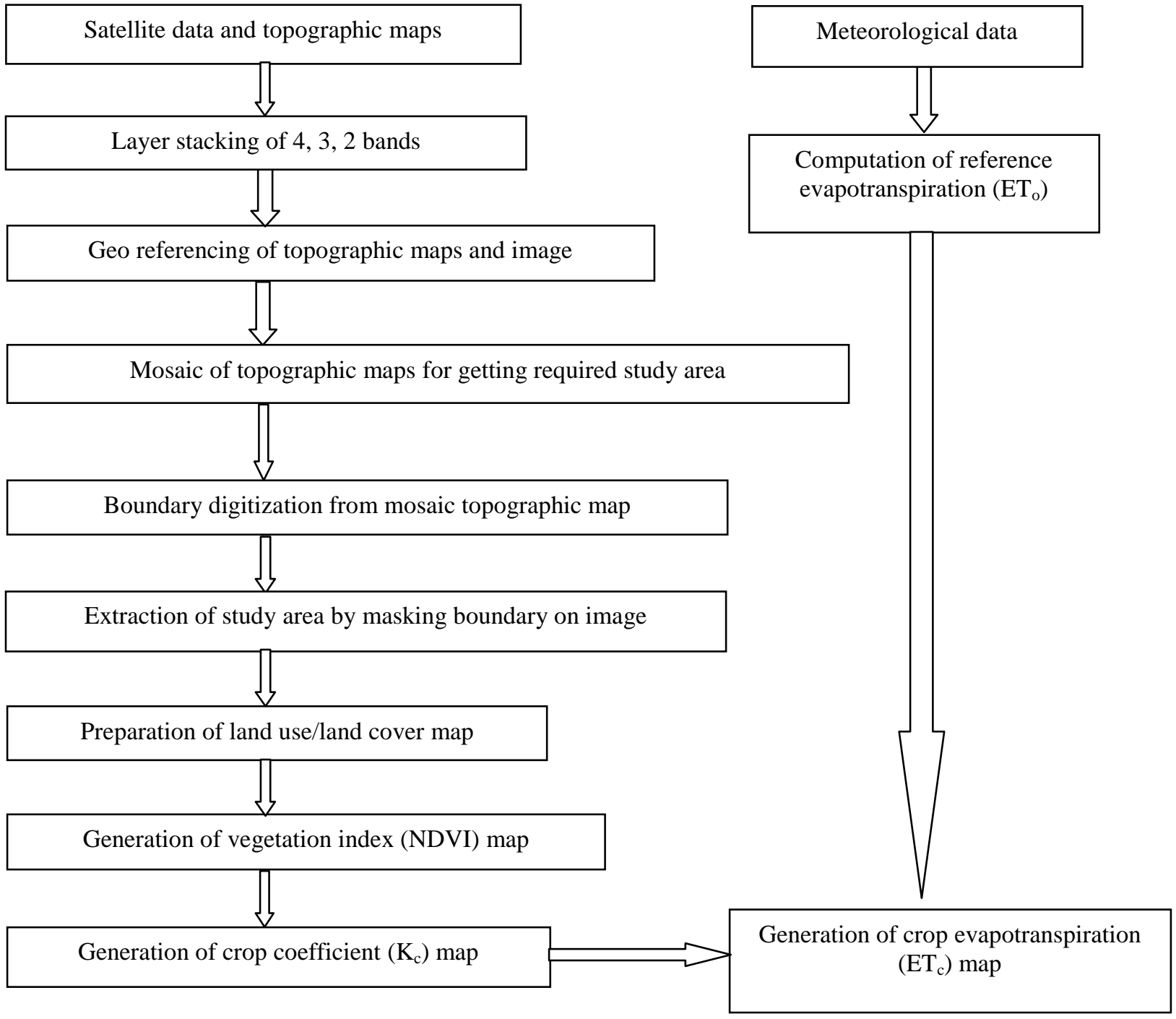

Fig. 4. Flow diagram for the estimation of crop evapotranspiration $\left(E T_{c}\right)$

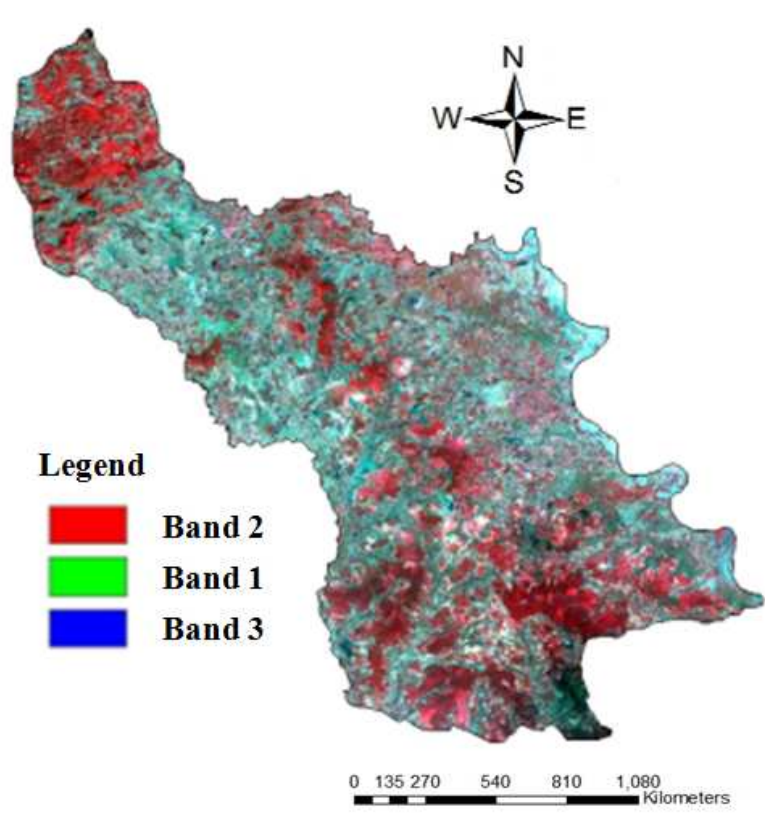

Fig. 5. FCC map for the study area

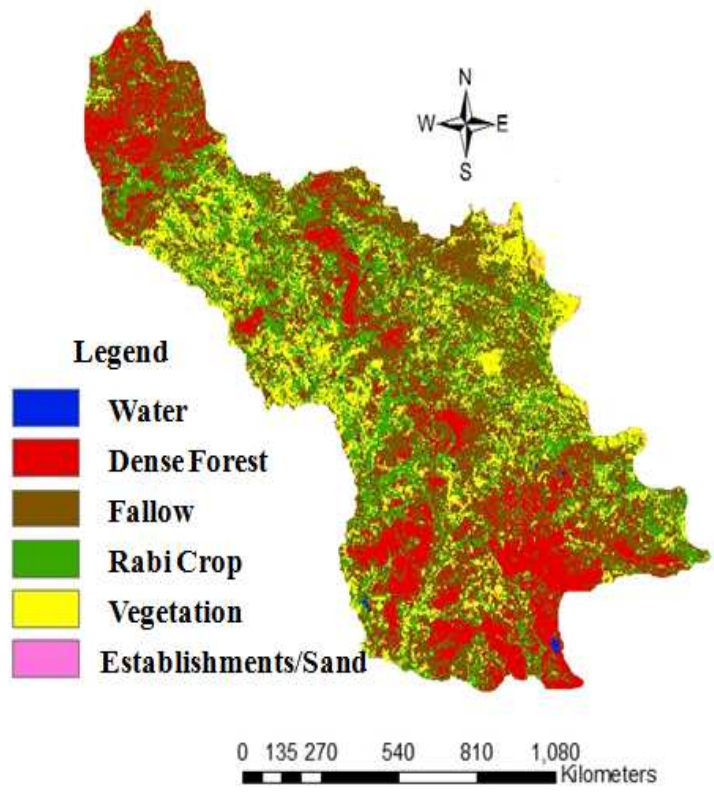

Fig. 6. Land use/Land cover map for the study area 


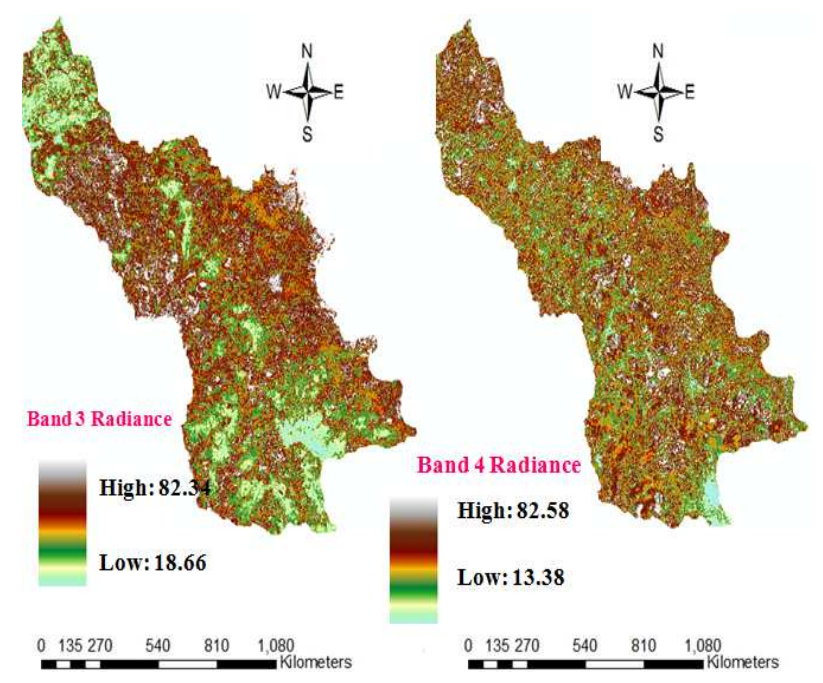

Fig. 7. Radiance maps generated for band 3 (Red) and band 4 (NIR).

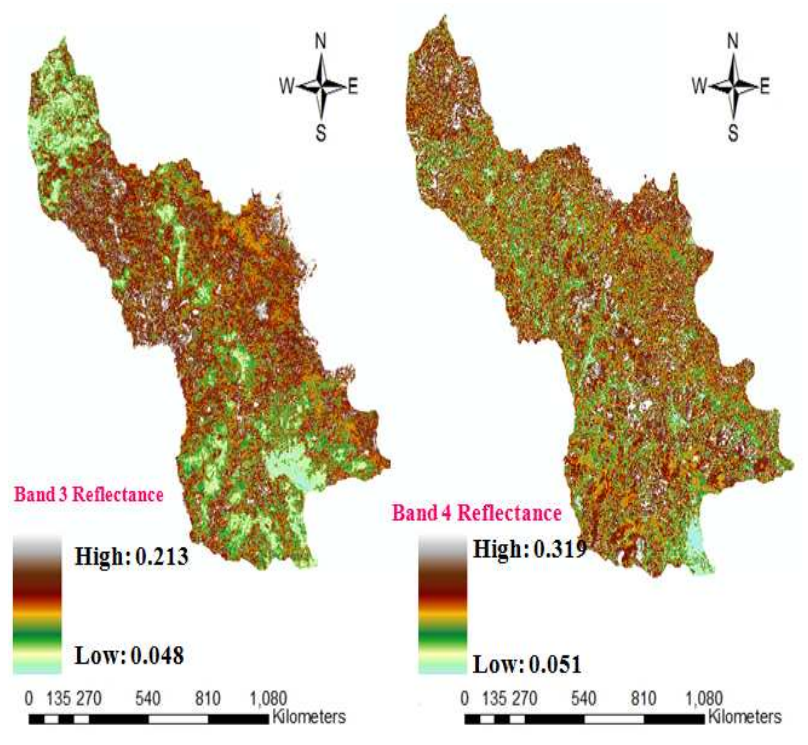

Fig. 8. Reflectance maps generated for band 3 (Red) and band 4 (NIR).

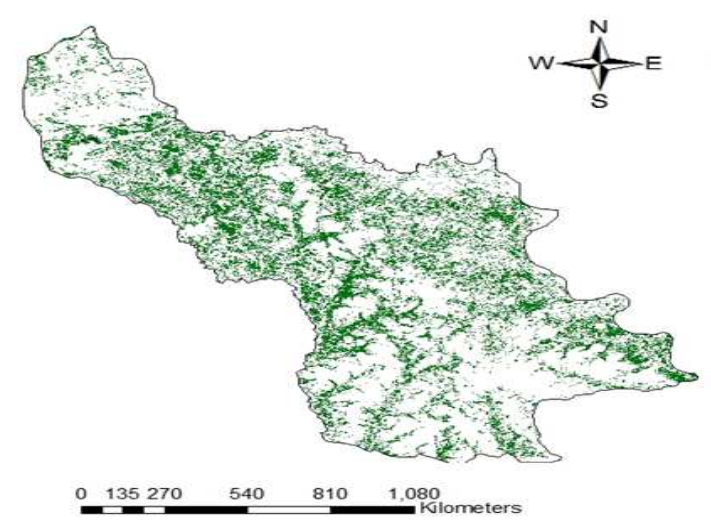

Fig. 11. Clipped map generated for only one land class of Rabi crop area.

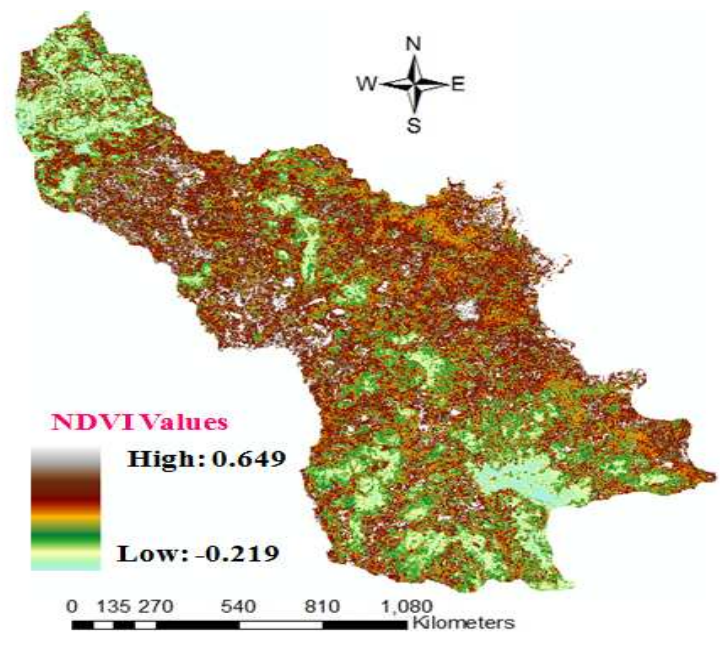

Fig. 9. NDVI map generated for the study area including all classes.

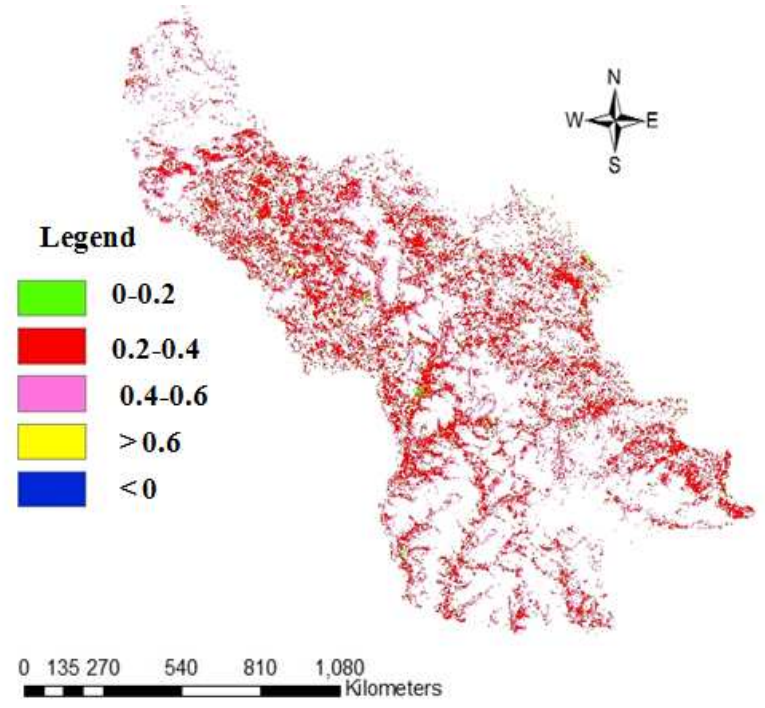

Fig. 10. NDVI map generated for clipped Rabi crop area.

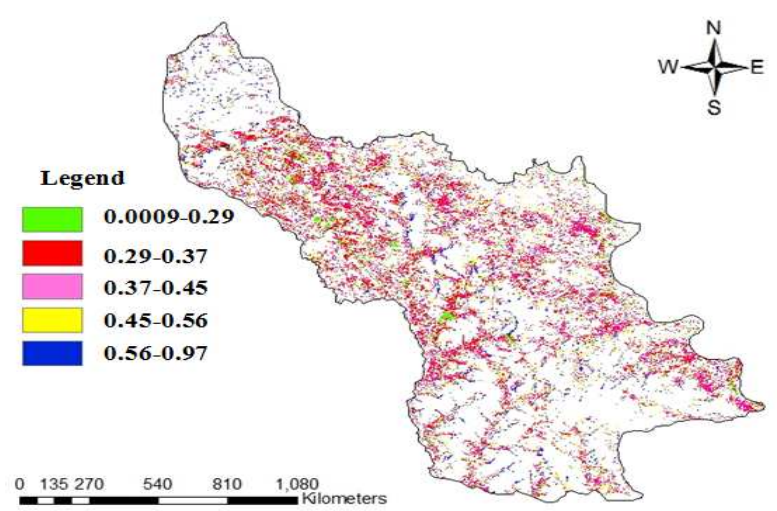

Fig. 12. Crop coefficient map generated for clipped Rabi crop area. 


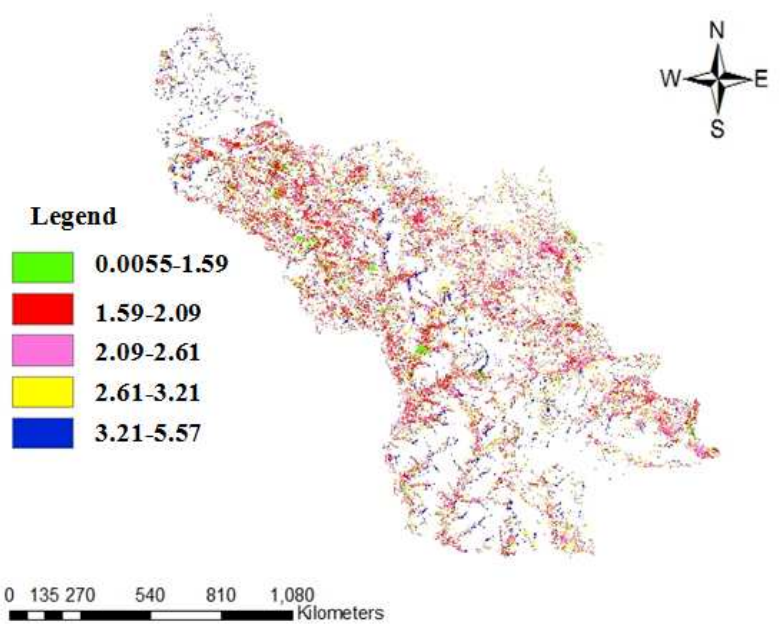

Fig. 13. Crop evapotranspiration map generated for clipped Rabi crop area.

day, whereas minimum was $1.59 \mathrm{~mm} /$ day. The results obtained are supporting the similar study conducted by Mishra et al. (2005) for paddy crop in TSMC irrigation command (West Bengal), Ray and Dadhwal (2000) in Mahi river irrigation command (Gujarat), and Gontia and Tiwari (2010) and Bhadra et al. (2009 and 2015) in TSMC command (West Bengal). Therefore, the information generated can be used to supply appropriate amount of irrigation water at different locations of irrigation command as per the actual crop water demand. This will save considerable amount of water supplied in the late growth stage of crop and improve the application efficiency of canal system. The study shows new vistas for application of remote sensing and GIS in water management of wheat crop.

\section{REFERENCES}

Adamala, S., Raghuwanshi, N. S., Mishra, A. and Tiwari, M. K. (2014). Evapotranspiration modeling using secondorder neural networks. Journal of Hydrologic Engineering, 19(6):1131-1140.

Allen, R. G., Pruitt, W. O., Raes, D., Smith, M. and Pereira, L. S. (2005). Estimating evaporation from bare soil and the crop coefficient for the initial period using common soils information. Journal of Irrigation and Drainage Engineering, 131(1):14-23.
Bandyopadhyay, P. K. and Mallick, S. (2003). Actual evapotranspiration and crop coefficients of wheat (Triticum Aestivum) under varying moisture levels of humid tropical canal command area. Agricultural Water Management, 59(1):33-47.

Bhadra, A., Bandyopadhyay, A., Raghuwanshi, N. S., Singh, R. (2009). Integrated reservoir-based canal irrigation model (IRCIM) - II: Application. ASCE Journal of Irrigation and Drainage Engineering, 135(2): 158-168. ISSN: 0733-9437 (Print), 1943-4774 (Online). DOI: 10.1061/(ASCE)0733-9437(2009)135:2(158).

Bhadra, A., Bandyopadhyay, A., Singh, R., and Raghuwanshi, N. S. (2015). Development and application of a simulation model for reservoir management. Lakes \& Reservoirs: Research \& Management, 20: 216-228. doi: 10.1111/ lre. 12106.

Brunsell, N. A. and Gillies, R. R. (2002). Incorporation of surface emissivity into a thermal atmospheric correction. Photogrammetric Engineering and Remote Sensing, 68 (12): $1263-1269$

Doorenbos, J. and Pruitt, W. O. (1977). Guidelines for predicting crop water requirements. FAO Irrigation and Drainage Paper No 24, FAO, Rome, Italy.

Gontia, N. K. and Tiwari, K. N. (2004). Crop evapotranspiration estimation using temporally distributed normalized difference vegetation index. Paper presented in international conference on emerging technologies in agricultural and food engineering held at IIT Kharagpur, India.

Gontia, N. K. and Tiwari, K. N. (2010). Estimation of crop coefficient and evapotranspiration of wheat (Triticum aestivum) in an irrigation command area using remote Sensing and GIS. Water Resource management, 24:1399-1414.

Jagtap, S. S. and Jones, J. W. (1989). Stability of crop coefficients under different climatic and irrigation management practices. Irrigation Science, 10:231-244.

Jayanthi, H., Nealea, C. M. U. and Wright, J. L. (2007). Development and validation of canopy reflectance based crop coefficient for potato. Agricultural Water Management, 88(1-3):235-246.

Manserud, R. A and Leemans, R. (1992). Comparing global vegetation maps with the kappa statistics. Ecological Modelling, 62:275-279.

Mishra, P., Tiwari, K. N., Chowdary, V. M. and Gontia, N. K. (2005). Irrigation water demand and supply analysis in the command area using remote sensing and GIS. Hydrology Journal IAH, 28(1-2):59-69.

Ray, S. S. and Dadhwal, V. K. (2000). Estimation of evapotranspiration of irrigation command area using remote sensing and GIS. Agricultural Water Management, 49:239-249. 